\title{
A Two Years Follow-Up Study of Children with Monosymptomatic Enuresis Treated with Enuresis Alarm
}

\author{
Berat Cem Ozgur ${ }^{1}$, Musa Ekici ${ }^{2}$, Tolga Karakan ${ }^{1}$, Ahmet Metin Hascicek ${ }^{1}$, Senem \\ Ozgur $^{3}$, Asim Ozayar $^{4}$, Cem Nedim Yuceturk $^{1}$ and Hasmet Sarici ${ }^{1}$ \\ ${ }^{1}$ Department of Urology, Ankara Education and Research Hospital, Turkey \\ ${ }^{2}$ Department of Urology, Ankara Diskapi Education and Research Hospital, Turkey \\ ${ }^{3}$ Department of Pediatrics, Ankara Dr Sami Ulus Children's Hospital, Turkey \\ ${ }^{4}$ Department of Urology, Ankara AtatUrk Education and Research Hospital, Turkey
}

Correspondence should be addressed to: Berat Cem Ozgur; bcemozgur@hotmail.com

Received 25 February 2013; Accepted 28 March 2013; Published 26 April 2013

Academic Editor: Patrina Caldwell

Copyright (C 2013 Berat Cem Ozgur, Musa Ekici, Tolga Karakan, Ahmet Metin Hascicek, Senem Ozgur, Asim Ozayar, Cem Nedim Yuceturk and Hasmet Sarici. Distributed under Creative Commons CC-BY 3.0

\begin{abstract}
Objective: Nocturnal enuresis is a common problem among children. This multifactorial disease is a source of stress of the families. Therefore, it is important how to approach the disorder, plan the treatment in order to provide a satisfactory cure rate. The aim of this study was to evaluate the long term results of alarm therapy after an initial response.
\end{abstract}

Materials Methods: The study consisted of 36 of 50 patients with nocturnal enuresis, that were responded alarm therapy after three months treatment. At the end of the second year, detailed interviews with the parents of the children were recorded.

Results: It was found that only $6(16.7 \%)$ patients achieved complete dryness with the alarm device and no different treatment modalities were needed after the initial success. The remaining $30(83.3 \%)$ patients had recurrence in the subsequent period and $25(\% 83.3)$ of them tried retreatment.

Conclusions: In long term follow up recurrence rates are high and families may seek different treatment approaches. Recurrence probabilities should be emphasized to the families at the beginning of the alarm treatment for monosymptomatic nocturnal enuresis.

Keywords: Enuresis nocturna, alarm treatment, relapse.

Cite this Article as: Berat Cem Ozgur, Musa Ekici, Tolga Karakan, Ahmet Metin Hascicek, Senem Ozgur, Asim Ozayar, Cem Nedim Yuceturk and Hasmet Sarici (2013), "A Two Years Follow-Up Study of Children with Monosymptomatic Enuresis Treated with Enuresis Alarm," Pediatrics Research International Journal, Vol. 2013 (2013), Article ID 318022, DOI: 10.5171/2013.318022 


\section{Introduction}

Nocturnal enuresis is a widespread problem among children. The prevalence estimates of enuresis are highly variable but approximately $15 \%$ of children wet the bed at night at age five, and there is a spontaneous resolution rate of about 15\% per year as Robson (2009) mentioned. The pathogenesis of enuresis nocturna is multifactorial and involves hormonal, functional, sleep-related, and psychological factors. Enuresis is categorized as monosymptomatic(MNE) and nonmonosymptomatic (NMNE) and also primary and secondary forms by Nevéus (2006). It is a source of stress for the children, as well as for their families, who may also incur significant financial costs. The literature reports a variety of potential treatments (e.g. enuresis alarms, imipramine, desmopressin, oxybutinin, and complex regimens such as dry-bed training and combined treatments etc.).Although they do take longer than pharmacological interventions to work and require effort from both the children and the families, alarms are recommended as a first-line treatment to be used after advice on fluids, toileting, and rewards, as the long-term success rate is satisfactory in the literature. The present study was conducted to evaluate the long term success rates of alarm therapy on monosymptomatic nocturnal enuresis. Information from this study should assist both health professionals and families in planning treatment strategies of MNE since responsiveness and relapses are important considerations when selecting an optimal outcome.

\section{Materials Methods}

Between January 2010 and August 2012, the prospective trial was conducted in healthy children aged 6-16 years, referred to the urology or paediatric clinics of two different centres, for significant monosymptomatic enuresis nocturna (defined as three or more wet nights per week). After detailed history taking and careful physical examination, patients with obvious growth retardation, positive urine analysis and positive urine cultures were excluded. Inclusion criteria of the patients included; having primary nocturnal enuresis, not receiving medical treatment for enuresis. Both the parent and child were given an explanation of the treatment rationale and a demonstration of the alarm system being used. The device consists of a battery-operated detector which is activated by urine and gives sound in order to wake up the child. Fluid intake was not restricted. The children were then asked to use the same type of enuresis alarm every night until they had completed a maximum trial period of 12 weeks. Our criterion of initial success was 14 consecutive dry nights before the conditioning therapy was stopped. According to the number of wet nights after 12 weeks of treatment, the patients were defined as responders or non-responders. A relapse was defined as the reappearance of $>1$ wet night per week for responders. Further follow-up data was maintained via telephone with a detailed interview with the parents of the children at the end of the second year. The results were assessed statistically using routine statistics and expressed as mean \pm standard deviation.

\section{Results}

Fifty children (27 boys/23 girls) with primary nocturnal enuresis were included for the study. The mean age of the patients was 8.1 (range 6-16) years and the mean follow-up time was 24 months. At the end of treatment at 12 weeks, all patients were seen in the clinic, and it was noted that 36 of $50(72 \%)$ patients had benefited from the enuretic alarm. After the interviews with the families at the end of the second year it was found that only $6(16.7 \%)$ patients achieved complete dryness with the alarm device and no different treatment modalities were needed after the initial success. The remaining $30(83,3 \%)$ patients had relapses in the subsequent period and 25 family tried retreatment (desmopressin, oxybutynin, alarm or combined treatment). 15 of those $(60 \%)$ patients, who tried different retreatment modalities reported complete dryness in that period. Also 5 patients left the treatment and one of them reported spontaneous recovery. At the end the second year, totally $22(61 \%)$ patients of the initial responders were improved. The results are summarized in Fig. 1. 


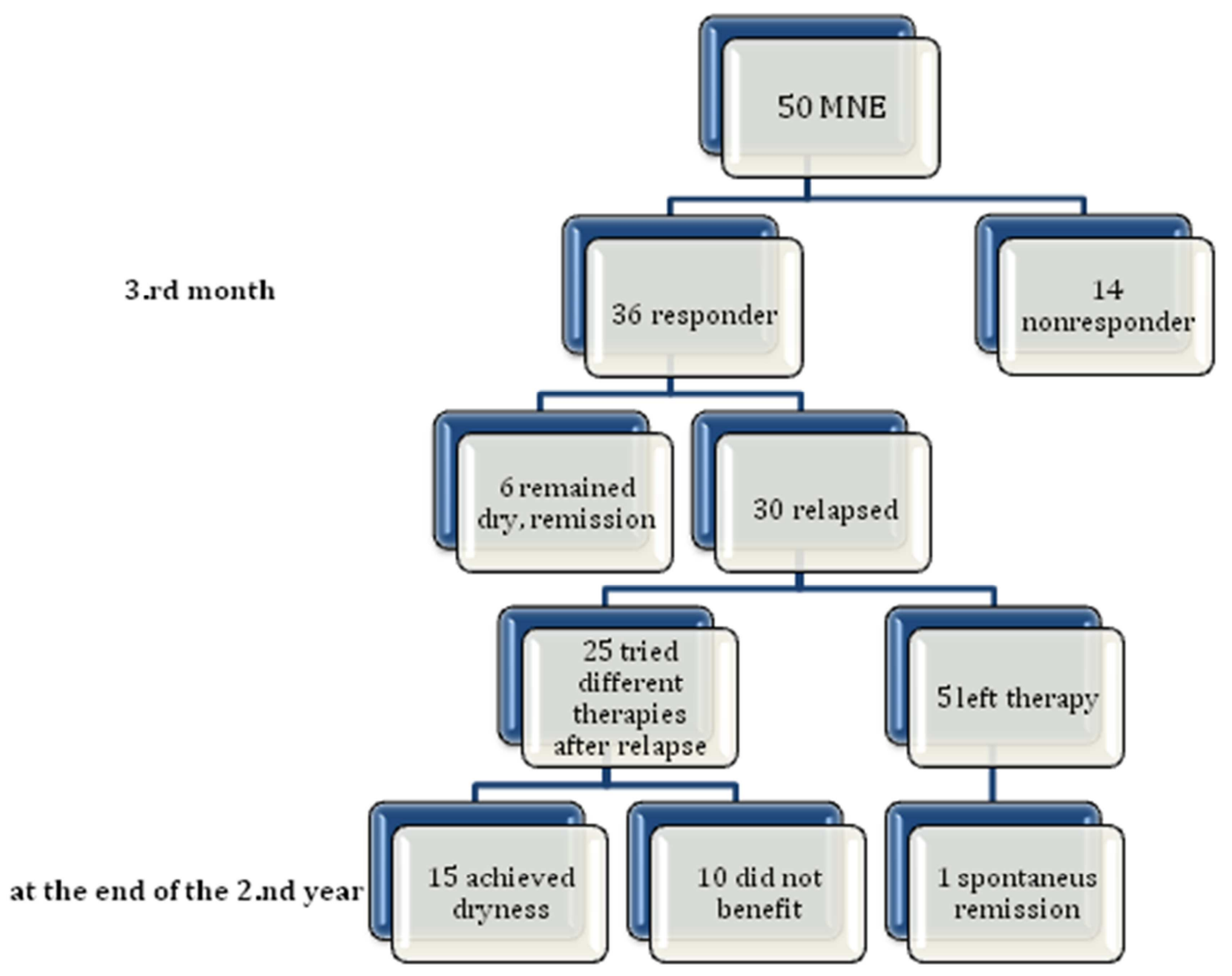

Fig.1. Timeline Chart Shows the Distribution of the Patients by Relapse and Response

\section{Discussion}

Nocturnal enuresis refers to involuntary loss of urine after the age of 5 years, when children are expected to have achieved full bladder control at night. The minimal frequency of nocturnal urine loss required to diagnose this condition has varied in different studies by Butler (2005), Kanaheswari (2003) and Brooks (2003). Our study group was, significant MNE, as defined three or more wet nights per week. Brown et al (2011) supported the urine alarm as one the most effective intervention for nocturnal enuresis and demonstrated the benefit of combining the urine alarm with other components, both behavioral and pharmaceutical. Alarms are recommended as a first-line treatment to be used in the literature but they require effort from both the children and their family. Children and families require access to advice and support in learning to use alarms and monitoring their effectiveness as O'Flynn (2011) mentioned. Previous studies report the use of alarm therapy for monosymptomatic nocturnal enuresis. These studies show promising results, but they suffer from lack of randomization and lack of a placebo-controlled patient group and are of small sample size. In addition to this, no predictive factors of response to that kind of therapy have been considered. Also follow up periods are usually less than one year.

Alarms achieve dryness by training the child to recognize the need to pass urine and to wake to go to the toilet or hold on over time .Fielding et al showed that, as such it would be expected that they would be most successful in patients with arousal difficulties rather than patients who are overproducing urine at night. The data about the relapse rates after alarm therapy varies in different studies. Kwak et al (2010) evaluated children with a full response for relapse 12 weeks after withdrawal of the treatment and they reported of the children with experienced a relapse of only $12 \%$. Wagner (1982) showed there was no statistically significant difference in the 
number of children relapsing at 6 months when treated with an enuresis alarm compared to imipramine after 14 weeks treatment and relapse rates are acceptable. But both Willie (1986) and Ng (2005) showed children treated with desmopressin were more likely to relapse at 3 months compared to children treated with an enuresis alarms after the end of 12 weeks treatment and their relapse rates are less than $10 \%$. Monda (1995) showed that, of the 79 patients treated with alarm therapy $63 \%$ were continent at 6 months and 56\% were dry at 12 months. In our study, the $72 \%$ initial success rate obtained by the participants is in accordance with previous results of Butler $(2002,2005)$, Fai -Ngo (2005) and Van Leerdam (2004) - 65\% on average. But as the relapse criterion was defined as more than one wet night per week after dryness was achieved our longterm data showed that relapse is the main problem of this therapy. 30 of the $36(83 \%)$ responder patients relapsed in two years time and that is much higher than many studies. There are several possible explanations for these findings. Our explanation is that; patients with MNE may be categorized into subgroups and our group consist of children with significant MNE as defined three or more wet nights per week and that group of patients have high probabilities to not only unresponsiveness but also high relapse rates. Longer follow up period might be another reason as more than half of the relapses were after six months period.

It was already reported by Hansen (1997) that the use of an alarm increased nocturnal bladder capacity, but had no effect on daytime bladder capacity, pelvic floor activity, sleep patterns, vasopressin secretion, or nocturnal urine output. All those factors may be the cause of the relapses in the present study. In a research study by Evans (2011) it was found that it would give the possibility of a family disruption since it was clearly shown that the withdrawal from the alarm group was high, indicating the importance of considering family motivation before selecting treatment, for optimal outcome. When considering the use of alarms, the child involved, as well as the parents/carers, should be informed that it may take a few weeks before the alarm starts to have an effect, and it may take weeks before dry nights are achieved and also if bedwetting restarts after stopping treatment, use of the alarm can be restarted without consulting a health professional as there is always a risk of that condition in long term period.

As the strength of our study that sets it apart from previous observations is the fact that two year follow up period, the present study has a number of limitations that should be mentioned. A large number of medical records were incomplete and consequently a great number of patients were excluded from the study causing a small sample size. Needless to say the spontaneous cure rate (15\% per year), would have cured some patients during the study period of two years. We did not observe a significant difference between children and adolescents, with both presenting similar success rates. However, with a broader sample, there might be a difference of the relapses between age groups. Another limitation of this study was the absence of a control group and also of an analysis to determine the variability between therapists in terms of the support provided. Also as the data was provided by the families' expression the exact time of the relapses were not clear although it was recorded that more than half of them were after six months of withdrawal.

In conclusion, although enuresis alarms were evaluated as part of original economic modeling and were shown to be a likely cost-effective first line treatment option, in long term follow up recurrence rates are high and families may seek different treatment approaches. Treatment of choice of that disease is still highly controversial, as the physiopathology is not yet fully understood and the pathogenesis is probably multifactorial: urinary reservoir abnormalities genetic and psychological factors, sleep disorders, urine production disorders can all play a part. Alarm treatment can also be combined with medical therapy in cases of refractory monotherapy or to increase the success rates and also in cases of relapsing patients. The findings of our study indicate that enuresis alarms offers high initial response for patients with MNE but relapses are 
higher than expected. A larger multicenter trial for the evaluation of long term outcome of that therapy and the factors for failure is needed. It is clear that we are dealing with a number of different therapeutic modalities and every patient is different than other, so the recurrence probabilities should be emphasized to the families at the beginning of the treatment.

\section{References}

Brooks, L. J. \& Topol, H. I. (2003). "Enuresis in Children with Sleep Apnea," Journal of Pediatrics, 142 515-8.

Brown, M. L., Pope, A. W. \& Brown, E. J. (2011). "Treatment of Primary Nocturnal Enuresis in Children: A Review," Child Care Health Development Journal, 37 153-60.

Butler, R. J., Golding, J. \& Heron, J. (2005). "Nocturnal Enuresis: A Survey of Parental Coping Strategies at 71/2 Years," Child Care Health Development Journal, 31 659-67.

Butler, R. J. \& Gasson, S. L. (2005). "Enuresis Alarm Treatment," Scandinavian of Journal Urology Nephrology, 39 349-57.

Butler, R. J. \& Robinson, J. C. (2002). "Alarm Treatment for Childhood Nocturnal Enuresis: An Investigation of WithinTreatment Variables," Scandinavian Journal of Urology Nephrology, 36 268-72.

Evans, J., Malmsten, B., Maddocks, A., Popli, H. S. \& Lottmann, H. UK Study Group. (2011). "Randomized Comparison of LongTerm Desmopressin and Alarm Treatment for Bedwetting," Journal of Pediatric Urology, 7 21-9.

Fai-Ngo Ng, C. \& Wong, S.- N. Hong Kong Childhood Enuresis Study Group. (2005). "Comparing Alarms, Desmopressin, and Combined Treatment in Chinese Enuretic Children," Pediatric Nephrology, 20 163-9.

Fielding, D. (1985). "Factors Associated with Drop-Out, Relapse and Failure in the Conditioning Treatment of Nocturnal Enuresis," Behavioral Psychotherapy, 13 174-85.
Hansen, A. F. \& Jorgensen, T. M. (1997). "Alarm Treatment: Influence on Functional Bladder Capacity," Scandinavian Journal of Urology Nephrology, 183 59-60.

Kanaheswari, Y. (2003). "Epidemiology of Childhood Nocturnal Enuresis in Malaysia," Journal of Pediatrics and Child Health, 39 118-23.

Kwak, K. W., Lee, Y. S., Park, K. H. \& Baek, M. (2010). "Efficacy of Desmopressin and Enuresis Alarm as First and Second Line Treatment for Primary Monosymptomatic Nocturnal Enuresis: Prospective Randomized Crossover Study," Journal of Urology, 184 2521-6.

Monda, J. M. \& Husmann, D. A. (1995). "Primary Nocturnal Enuresis: A Comparison among Observation, Imipramine, Desmopressin Acetate and Bed-Wetting Alarm Systems," Journal of Urology, 154 745-8.

Nevéus, T., Von Gontard, A., Hoebeke, P., Hjalmas, K., Bauer, S. \& Bower, W. (2006). "The Standardization of Terminology of Lower Urinary Tract Function in Children and Adolescents: Report from the Standardization Committee of the International Children's Continence Society," Journal of Urology, 176 314-24.

Ng, C. F. \& Wong, S. N. (2005). "Hong Kong Childhood Enuresis Study Group. Comparing Alarms, Desmopressin, and Combined Treatment in Chinese Enuretic Children," Pediatric Nephrology, 20 163-9.

O'Flynn, N. (2011). "Nocturnal Enuresis in Children and Young People: NICE Clinical Guideline," British Journal of General Practice, 61 360-2.

Robson, W. L. M. (2009). "Clinical Practice. Evaluation and Management of Enuresis," New England Journal of Medicine, 360 142936.

Van Leerdam, F. J. M., Blankespoor, M. N., Van Der Heijden, A. J. \& Hirasing, R. A. (2004). "Alarm Treatment is Successful in Children with Day- and Nighttime Wetting," Scandinavian Journal of Urology Nephrology, 38 211-5. 
Wagner, W., Johnson, S. B., Walker, D., Carter, R. \& Wittner, J. (1982). "A Controlled Comparison of Two Treatments for Nocturnal Enuresis," Journal of Pediatrics, 101 302-7.

Wille, S. (1986). "Comparison of Desmopressin and Enuresis Alarm for Nocturnal Enuresis," Archives of Disease in Childhood, 61 30-3.

Berat Cem Ozgur, Musa Ekici, Tolga Karakan, Ahmet Metin Hascicek, Senem Ozgur, Asim Ozayar, Cem Nedim Yuceturk and Hasmet Sarici (2013), Pediatrics Research International Journal, DOI: 10.5171/2013.318022 